Sociedad e Infancias

ISSN: 2531-0720

http://dx.doi.org/10.5209/SOCI.56415

\title{
Infancia vulnerable en los medios de comunicación
}

\author{
María Jesús Rodríguez Costa ${ }^{1}$
}

Desde hace varios años la organización internacional dedicada a la infancia, Aldeas Infantiles SOS, y la Federación de Asociaciones de Periodistas de España (FAPE) han analizado la información que sobre los niños y los jóvenes aparece en la prensa española, animando a los profesionales a realizar su trabajo con rigor y ética, evitando aportar datos que permitan identificar a los menores que están bajo la tutela de la Administración o caer en el morbo o sensacionalismo que alertan a la población. Con este objetivo, ambas entidades han realizado varias publicaciones.

En 2016 se unió al tándem el Consejo General de la Abogacía Española, con la intención de aportar su análisis del marco legislativo para la protección de la infancia. Juntas, las tres entidades presentaron el año pasado el Informe 2016-La infancia vulnerable en los medios de comunicación. Hacia la calidad informativa en el que varios expertos analizan el tratamiento informativo en noticias sobre menores vulnerables aparecidas en la prensa escrita española entre septiembre de 2015 y junio de 2016.

Este trabajo continúa el realizado en años previos y sus conclusiones son claras: "el tratamiento informativo en relación con la infancia vulnerable progresa adecuadamente", si bien, "los periodistas deben seguir extremando el celo y apelando a su ética profesional para que cada vez menos informaciones pequen de la vulneración de los derechos de los niños". Pero veamos cuál es el punto de partida de este trabajo.

\section{Un proyecto con varios años de desarrollo: primera etapa}

La colaboración entre Aldeas Infantiles SOS y la FAPE comenzó en 2014 con el Código ético para la infancia vulnerable. El proyecto nació con la intención de proteger en los medios de comunicación a los niños y jóvenes en situación de riesgo e informar de su realidad desde la ética. La organización quería cuidar este aspecto y para hacerlo pidió la ayuda de expertos en la materia.

Esta publicación contó con las aportaciones de periodistas expertos y especializados en temas sociales de diversos medios de comunicación y agencias informativas que participaron, durante varios meses, en reuniones de trabajo y en un proceso de consulta, mediante encuestas, dirigido por Aldeas Infantiles SOS. Los resultados de las consultas y los debates realizados durante las sesiones de trabajo permitieron

Aldeas Infantiles SOS de España

E-mail: mrodriguez@aldeasinfantiles.es 
poner en común las impresiones acerca de la profesión y sus límites al elaborar las noticias. Las ilustraciones se realizaron aludiendo también al cuidado de la infancia y fueron aportadas por profesionales de la ilustración que colaboran habitualmente en medios de comunicación.

El resultado fue esta publicación que, lejos de pretender decir a los periodistas cómo se debe escribir, articula una serie de consejos útiles que favorezcan el buen hacer de los periodistas al elaborar informaciones sobre la infancia vulnerable. De este modo, se establecieron las siguientes pautas para un correcto tratamiento de la infancia vulnerable:

- Deben primar los principios éticos.

- Apelar al rigor y celo profesional.

- Contrastar siempre la información con otras fuentes.

- La intimidad personal y familiar, el derecho al honor y la propia imagen, y el interés superior del niño.

- Debemos informar de los niños como si fueran nuestros propios hijos.

- No magnificar y no alarmar.

- Favorecer la especialización de los periodistas.

- Contextualizar los sucesos.

- No utilizar el morbo ni el sensacionalismo, sobre todo en los titulares.

- Resaltar lo positivo antes que lo negativo.

- Las redes sociales no son dogma de fe: educar para un uso correcto.

- Cuesta lo mismo escribir una buena información que una mala: trabajemos con autocrítica.

- Respeto hacia la identidad de los niños.

- Denuncia de las vulneraciones de sus derechos.

- Evitar referencias al niño o su familia por su procedencia o religión.

- Evitar dar datos que identifiquen a un niño bajo el sistema de protección.

- Los niños no deben hacer declaraciones a los medios de comunicación ante hechos que vulneren su intimidad.

El Código ético para la infancia vulnerable fue presentado en noviembre de 2014, y fue muy bien acogido en el sector. Por primera vez existía una guía de estas características para periodistas, siguiendo el modelo de otras publicaciones para el tratamiento informativo de colectivos vulnerables como en el ámbito de la discapacidad, donde ha habido precedentes similares.

\section{Segunda etapa}

El proyecto continuó con una segunda etapa en la que se planteó dar un paso más y analizar "el estado de la cuestión" en cuanto a infancia vulnerable en los medios de comunicación españoles, analizando qué se publica, qué temas interesan y cómo se tratan, a qué públicos se orientan, qué medios cuidan más sus informaciones y cuáles menos, para hacer una valoración y presentarla a la profesión y a la sociedad.

Por ello, se estableció un nuevo proceso de trabajo que consistió en seleccionar informaciones sobre infancia de la prensa escrita española bajo las premisas ante- 
riormente citadas, buscando en una variedad amplia de medios noticias publicadas entre enero y agosto de 2015.

Entre septiembre y octubre, cuatro expertos analizaron el tratamiento que daban a la infancia vulnerable 45 informaciones aparecidas en prensa durante los meses previos, estudiando las noticias desde tres áreas de análisis:

- No utilizar el morbo ni el sensacionalismo, sobre todo en los titulares. El titular debe llamar la atención del lector, oyente o telespectador, pero debemos tener cuidado en no traspasar la delgada línea que separa un titular atractivo de uno que genera morbo.

- No marginar ni alarmar. El periodista debe ceñirse a la verdad. Lo único que se puede conseguir alarmando a los ciudadanos con una información es perder la propia credibilidad.

- Resaltar lo positivo antes que lo negativo, buscando aspectos positivos en nuestra información. La manera de tratar una información o de extrapolar los datos de una estadística que habla sobre infancia es esencial para que el resultado ofrezca ese cariz positivo.

Tras una puesta en común de los expertos y una elaboración de conclusiones se publicó el Informe 2015-La infancia vulnerable en los medios de comunicación, tu reflexión y sensibilidad suman, que se presentó también a final de año, con motivo del Día Internacional de los Derechos de los Niños, celebrado internacionalmente el 20 de noviembre.

En esta ocasión las conclusiones señalaban que, aunque la mayor parte de las noticias revisadas realizaban un correcto tratamiento de los temas relativos a la infancia, todavía se encontraban algunas informaciones que no protegían adecuadamente la intimidad y el honor de los niños que las protagonizaban y que eran, la mayoría de las veces, las víctimas.

Asimismo, se señalaba que el periodista debe tener muy presente la percepción del lector cuando lea una noticia, por lo que se hace necesaria la reflexión en el titular, el primer párrafo y los sumarios. Por otro lado, debe contrastar la noticia con más de una fuente $y$, sin duda, es recomendable la consulta de expertos.

En las redacciones debe realizarse la reflexión de la utilidad de publicación, ya que algunas noticias que no aportan nada y sólo pueden perjudicar la imagen de una persona menor de edad. Asimismo, el informador debe ejercitar la autocensura si los padres se han excedido en sus funciones de progenitores y está en cuestión la dignidad de sus hijos, extremando la protección. Y deben evitar juzgar o establecer culpables cuando se escribe sobre delitos cometidos por menores.

\section{Tercera fase: Metodología de trabajo y proyecto 2016}

El año siguiente las entidades promotoras del proyecto se plantearon otro nuevo avance: lograr rigor y la excelencia de la información. Para el nuevo estudio se seleccionaron un total de 5.673 noticias relacionadas con menores publicadas en prensa escrita. En el periodo de septiembre de 2015 a junio de 2016 se hizo una preselección de 200 noticias. Tras el análisis de esa preselección por expertos, se extrajo una 
selección final de 70 noticias que engloban una variedad de temáticas y tratamientos informativos.

Una vez seleccionadas las 70 informaciones finales, se enviaron junto con una serie de criterios de valoración respecto a los titulares, contenidos y fotografías a los expertos, para que realizaran sus análisis y conclusiones. En septiembre se realizó una jornada de puesta en común. Con los resultados obtenidos, se elaboraron estadísticas de valoración de los resultados y los recogieron en gráficos que reflejaban los hallazgos.

El análisis realizado no tuvo en cuenta las cabeceras de los periódicos ni las firmas de los periodistas, sino el tratamiento periodístico que reciben a modo de reflexión y orientación para que las informaciones de infancia resulten cada día mejor elaboradas. En concreto, la investigación analizó las noticias teniendo en cuenta tres puntos del Código Ético que se consideran fundamentales para realizar una buena información sobre temas de infancia o cuyos protagonistas directos o indirectos sean los niños:

- "Respeto hacia la identidad de los niños, ya que siempre debe ser protegida de modo que sus circunstancias no puedan suponer un estigma. Por encima de todo debemos ser los máximos protectores de la identidad de los niños que protagonicen nuestras noticias. Ni siquiera debemos contextualizar su círculo social para evitar que puedan ser identificados en su ambiente más cercano. Los periodistas contamos con recursos suficientes para no develar ningún dato que pueda poner en peligro la identidad del niño".

- "Evitar referencias al niño o su familia por su procedencia o religión. Las denominaciones xenófobas o despectivas no son admisibles, ni suelen ser relevantes para la información. Da igual la procedencia o sus creencias religiosas, lo importante es que son niños los que aparecen en la noticia”.

- "Evitar dar datos que identifiquen a un niño bajo el sistema de protección (nombre, datos personales, raza, identidad sexual, etc.). Los niños que viven bajo un sistema de protección (una Aldea Infantil SOS, una familia de acogida u otra medida) pueden verse estigmatizados si sale a la luz el lugar donde viven, que en muchos casos puede obviarse. Son niños totalmente socializados, cuya única particularidad es que viven separados de sus padres en un entorno diferente al biológico".

Tras el análisis exhaustivo de las noticias, se consideró que, en términos generales, había más informaciones bien elaboradas que las analizadas en el informe de 2015, aunque en su mayor parte eran sucesos. Aun teniendo en cuenta esta afirmación, se hace constar como hecho preocupante que todavía haya casos en los que, por ejemplo, se desvela la identidad de los menores o de su entorno familiar. En las fotografías publicadas se apreciaba un mayor cuidado para no vulnerar la imagen de los niños.

\section{Conclusiones}

El tercer informe publicado, La infancia vulnerable en los medios de comunicación, hacia la calidad informativa, pretende apelar a la ética profesional y al rigor para 
elaborar una información sobre infancia, ya que es un periodo fundamental en la vida de cada persona. En él se demanda a los periodistas su colaboración, "necesaria para el progreso de nuestra sociedad", señalando que "los grandes problemas sociales empiezan a cambiar cuando los medios se hacen eco de ellos".

Una de las expertas señala que "el Periodismo representa un papel esencial en la sociedad para crear criterio en la ciudadanía. Una función de denuncia ante la injusticia, la corrupción o la desigualdad. Para dar voz al más débil e indefenso". Y remarca otro experto jurista que la legislación debe "proteger al menor, no sólo desde la inmediatez, sino a largo plazo, tratando de que los errores que se hayan podido cometer o las circunstancias en las que se haya desarrollado la vida del menor, tengan el impacto social más leve posible en su vida de adulto a fin de garantizar una cierta igualdad de oportunidades".

\section{Continuidad del proyecto}

La misión de Aldeas Infantiles SOS, que trabaja en 134 países, es proteger a la infancia vulnerable en todos los ámbitos. En este sentido, ha de llevar a cabo iniciativas en lo que respecta al tratamiento informativo pues, aunque la mayoría de las veces los medios hacen un trabajo excelente, hay ocasiones en las que no se han tratado con respeto a los niños, se han desvelado datos de su identidad o se ha descalificado a ellos o a su familia.

En sus años de experiencia, la ONG ha hecho acopio de varios ejemplos de un mal tratamiento informativo hacia la infancia que ha podido repercutir en el desarrollo adecuado de los niños. Para evitarlo y para formar también a las nuevas generaciones de periodistas especializados en noticias del ámbito social, hecho fundamental, se continuará trabajando en la defensa de la ética informativa y ya se ha empezado a trabajar en un nuevo reto: ampliar el análisis a la prensa digital y descubrir si es heredera de los mismos aciertos y errores en las noticias sobre infancia vulnerable. El resultado se verá en el próximo informe 2017. 